\title{
Marine and human habitat mapping for the Coral Triangle Initiative region of Sabah using Landsat and Google Earth imagery
}

\begin{abstract}
The governments of the six Coral Triangle Initiative (CTI) countries, namely Indonesia, Malaysia, Philippines, Timor Leste, Papua New Guinea and the Solomon Islands have expressed their commitment to protecting marine ecosystems and improving management systems. Achieving the above commitment requires detailed baseline information on the spatial distribution and extent of the marine resources, such as seagrass meadows, coral reef, mangrove forests and seaweed beds, as well as the ability to successfully interpret and understand these data. This study examined a combination of Landsat image enhancement technique and pixel-based regional growing tools to create a map of marine and human habitats with five classes-of-interest: seagrass, land, coral and coral rubble, subsurface sand/mud, land, and human habitats for twelve islands of eastern Sabah of East Malaysia (extending from $4^{\circ} 42^{\prime} \mathrm{N}, 118^{\circ} 31^{\prime} \mathrm{E}$ to $4^{\circ} 12^{\prime} \mathrm{N}, 118^{\circ} 50^{\prime} \mathrm{E}$ ), located in the south-eastern boundary of Palawan/North Borneo Ecoregion (extending from $14^{\circ} 31^{\prime} \mathrm{N}, 116^{\circ} 52^{\prime}$ E to $0^{\circ}$ $0.04^{\prime} \mathrm{N}, 122^{\circ} 12^{\prime} \mathrm{E}$ ) of the CTI implementation area. Using this method, an overall accuracy of $>75 \%$ was achieved for mapping of those class-of-interest types. The estimated seagrass areal coverage is 274 ha, of which 158 ha (58\% of the total area) occurred in relatively shallow water areas. Using Google Earth data, seaweed culture sites with a total area of 7114 ha were observed around 7 of the 12 islands. The mapping approach and the results of the study will be of immense benefit to natural resource management of the study area through enabling conservation agencies to prioritize seagrass, coral, seaweed or marine conservation sites and to document local threats to those habitats.
\end{abstract}

Keyword: Seagrass distribution; Coral; Marine protected area; Coral triangle; Landsat; Sabah; Malaysia 